\title{
Minimally invasive perventricular device closure of perimembranous ventricular septal defect without cardiopulmonary bypass: Multicenter experience and mid-term follow-up
}

\author{
Quansheng Xing, MD, ${ }^{\mathrm{a}}$ Silin Pan, MS, ${ }^{\mathrm{a}}$ Qi An, MD, ${ }^{\mathrm{b}}$ Zewei Zhang, MD, ${ }^{\mathrm{c}}$ Jianhua Li, MD,${ }^{\mathrm{c}}$ Feng Li, MD, ${ }^{\mathrm{d}}$ \\ Qin Wu, MS, ${ }^{\mathrm{a}}$ and Zhongyun Zhuang, $\mathrm{MS}^{\mathrm{e}}$
}

Objective: To summarize the clinical experiences and mid-term follow-up results of perventricular closure of perimembranous ventricular septal defect without cardiopulmonary bypass under transesophageal echocardiography guidance.

Methods: A total of 408 patients with perimembranous ventricular septal defects, aged 5 months to 15 years $(3.1 \pm 1.7$ years) with a body weight of 4.5 to $26 \mathrm{~kg}(13.6 \pm 5.5 \mathrm{~kg})$, underwent perventricular device closure. The procedure was performed via a small lower sternal incision. A guidewire was inserted through the ventricular septal defect to the left ventricle under transesophageal echocardiography guidance after a pursestring suture was placed on the right ventricular free wall. A modified delivery sheath was introduced over the guidewire to establish the delivery pathway. Proper devices were delivered and then deployed if no atrioventricular or aortic valvular disturbance, or residual shunt was detected by transesophageal echocardiography. Patients were followed up with a standard protocol, which is once every month in the first 3 postoperative months and then once every 3 months with echocardiography, electrocardiography, and chest radiography in each follow-up.

Results: A total of 393 patients in this group underwent successful closure $(96.3 \%)$, and the procedure was converted to conventional open repair in 15 patients (3.7\%). A total of 213 symmetric devices $(54.2 \%)$ and 180 asymmetric devices $(45.8 \%)$ were implanted. Only 6 of the 393 patients $(3.5 \%)$ received transfusion of blood products. New trivial or mild tricuspid regurgitation was found in 13 patients $(3.3 \%)$, and there was no worsening of regurgitation in those patients with existing tricuspid regurgitation before operation. Eleven patients $(2.8 \%)$ had incomplete right bundle branch block. Most of the patients were discharged 3 to 5 days after the operation. Follow-up in all patients ranged from 3 months to 2 years (14.6 \pm 6.2 months) and revealed no residual shunt, new or aggravating aortic regurgitation, obstruction of left or right ventricular outflow tract, or device dislocation.

Conclusion: Minimally invasive perventricular device closure of ventricular septal defect without cardiopulmonary bypass is a simple, effective, and relatively safe intervention under guidance of transesophageal echocardiography. This method should be considered for patients with ventricular septal defect. Long-term follow-up is necessary. (J Thorac Cardiovasc Surg 2010;139:1409-15)

Perventricular device closure (PVDC) of ventricular septal defect (VSD) without cardiopulmonary bypass (CPB) under transesophageal echocardiography (TEE) guidance is increasingly being used. ${ }^{1-5}$ In 2007 , Xing and colleagues ${ }^{6}$ reported successful closure of a perimembranous ventricular

\footnotetext{
From the Heart Center, ${ }^{\text {a }}$ Qingdao Children's Hospital, Qingdao, China; Department of Cardiothoracic Surgery, ${ }^{b}$ West China Hospital, Sichuan University, Chengdu, China; Department of Cardiothoracic Surgery, ${ }^{\mathrm{c}}$ Children's Hospital, Zhejiang University, Hangzhou, China; Department of Cardiothoracic Surgery, ${ }^{\mathrm{d}}$ Shanghai Chest Hospital, Shanghai, China; and Shanghai Xingzhuangjiyi Alloy Material Corp, ${ }^{\mathrm{e}}$ Shanghai, China.

Disclosures: None.

All authors contributed equally.

Read at the 5th World Congress of Pediatric Cardiology and Cardiac Surgery, June 21 to 26, 2009, Cairns, Australia.

Received for publication June 29, 2009; revisions received Dec 8, 2009; accepted for publication Jan 8, 2010; available ahead of print April 5, 2010.

Address for reprints: Quansheng Xing, MD, Heart Center, Children's Hospital, 27 Wuding Rd, Qingdao, Shandong 266011 China (E-mail: qsxing@163.com). $0022-5223 / \$ 36.00$

Copyright (C) 2010 by The American Association for Thoracic Surgery doi:10.1016/j.jtcvs.2010.01.018
}

septal defect (PMVSD) with a newly designed delivery system using this technique. Subsequently, this new technique has been widely used in China. ${ }^{6-13}$ According to the device manufacturer (Shanghai Xingzhuangjiyi Alloy Material Corp, Shanghai, China), more than 1000 cases of PVDC were performed between March 2007 and April 2009. We retrospectively reviewed 408 patients in the 5 heart centers pioneering this new intervention technique and summarized the mid-term results.

\section{PATIENTS AND METHODS \\ Case Data}

Between March 2007 and April 2009, 408 patients with isolated PMVSD, aged 5 months to 15 years $(3.1 \pm 1.7$ years) with a body weight of 4.5 to $26 \mathrm{~kg}(13.6 \pm 5.5 \mathrm{~kg})$, underwent minimally invasive PVDC under TEE guidance.

Patients were enrolled in our program for the following indications: repeated respiratory infection ( $>6$ times per year); slow body development; heart enlargement observed on chest x-ray; left atrium enlargement observed on echocardiography (left atrium/aorta ratio $>1.5$ ); and left 


$$
\begin{aligned}
& \text { Abbreviations and Acronyms } \\
& \begin{aligned}
\text { AVB } & =\text { atrioventricular block } \\
\mathrm{CPB} & =\text { cardiopulmonary bypass } \\
\mathrm{LV} & =\text { left ventricle } \\
\mathrm{PMVSD} & =\text { perimembranous ventricular septal } \\
& \text { defect } \\
\text { PVDC } & =\text { perventricular device closure } \\
\mathrm{RV} & =\text { right ventricle } \\
\text { TEE } & =\text { transesophageal echocardiography } \\
\text { VSD } & =\text { ventricular septal defect }
\end{aligned}
\end{aligned}
$$

ventricular (LV) enlargement observed on echocardiography (LV enddiastolic diameter $>2$ standard deviations). The following patients were excluded: those with nonrestrictive or malaligned VSDs, those with VSDs with significant aortic prolapse, newborn or young infants with a large VSD and pulmonary hypertension, and patients who could not be followed.

Among our group, $213(52.2 \%)$ were boys. A total of 129 patients $(31.6 \%)$ in this group were excluded from transcatheter closure by cardiologists for different reasons, such as relatively large VSD dimension compared with low body weight or close proximity to the aortic valve. VSD size, measured by 2-dimensional transthoracic echocardiography, ranged from 3 to $12 \mathrm{~mm}(5.3 \pm 1.6 \mathrm{~mm})$. TEE was performed before device implantation to determine the shape and size of the VSD, and adjacent structures. An informed consent was signed by each family before operation. This technique was approved by the institutional review board.

\section{Devices and Delivery System}

The Occluder (No. 20043770007) used in this cohort was a modified form derived from the Amplatzer (AGA Medical Corp, Plymouth, MN) VSD closure device and was designed and manufactured by Shanghai Xingzhuangjiyi Alloy Material Corporation. Two types of occluders were supplied: concentric (symmetric) and eccentric (asymmetric) (Figure 1). The device consisted of a short waist, a left disk, and a right disk. The device size was chosen according to the diameter of the VSD. We recommended a device with a waist size 1 to $2 \mathrm{~mm}$ larger than the VSD diameter, an eccentric occluder for patients with a VSD margin less than $2 \mathrm{~mm}$ from the aortic valve, and a concentric occluder for other types of VSDs.

The total length of the device ranged from 10 to $20 \mathrm{~cm}$. The entire delivery system was modified by Dr Xing and consisted of an $18 \mathrm{G}$ trocar, a flexible guidewire, a dilator, a delivery sheath, and a loading sheath (Figure 2). The occluder (with a screw nut on it) was connected to the delivery cable (with a screw bolt on it) after rotating clockwise and then retracted into the loading sheath. After the delivery sheath was passed through the VSD, the occluder was advanced across the VSD and rotated counterclockwise to release the occluder.

\section{Procedure}

Patients were placed in a supine position under general anesthesia. The TEE probe was inserted. A 3- to 4-cm incision was made in the inferior sternum, and a pericardiotomy was performed. The free right ventricular (RV) surface was exposed. To determine the puncture site, the RV free wall was slightly palpated to locate the area of maximal thrill corresponding to the VSD location. A pursestring suture was placed at this location. The free wall was punctured within the suture using a trocar, the needle was removed, and a hyperechogenic guidewire was inserted. The guidewire was advanced through the RV cavity, slowly advanced toward the shunt orifice in the RV under TEE guidance, and then advanced across the VSD to the LV cavity. An imaging plane was selected to clearly view the RV orifice and guidewire.
A modified delivery sheath was introduced over the guidewire to the LV, establishing the delivery pathway. The occluder was advanced along the sheath and released after confirmed by TEE, as previously described. ${ }^{6-12}$ We reiterate that 2 tips should be used to ensure that the eccentric occluder is released in an appropriate position, particularly in patients in whom the VSD is close to the aortic valve. First, a special mark is made on the loading sheath after the device is retracted in the loading sheath to indicate the flat surface of the eccentric occluder. Second, the operator can adjust the device by the platinum mark (on the eccentric side of the left disk) to make the hyperechogenic platinum mark rightly deviate from the aortic valve and face the heart apex (Figures 3-7). This maneuver ensures correct and easy delivery of the occluder. The device can be easily retracted and redeployed in case of inappropriate position of the occluder causing valvular regurgitation or LV or RV outflow tract obstruction. When necessary, another puncture site on the RV free wall can be chosen. In our group, 11 patients $(2.7 \%)$ had multiple RV punctures.

\section{RESULTS}

\section{Intraoperative and Early Postoperative Period}

A total of 393 patients $(96.3 \%)$ in this cohort underwent perventricular closure of VSDs, and the procedure was converted to conventional open repair in the remaining 15 patients $(3.7 \%)$. Of the successful PVDC cases, symmetric devices were implanted in 213 patients $(54.2 \%)$ and asymmetric devices were implanted in the remaining patients. A total of 387 patients $(96.5 \%)$ did not require transfusion of blood products.

New trivial or mild tricuspid regurgitation was detected in 13 patients $(3.3 \%)$ by intraoperative TEE. None of the patients had more than a mild degree of regurgitation, and no worsening regurgitation was observed in those with existing tricuspid regurgitation before surgery. No obvious residual shunt or aortic regurgitation was detected.

Incomplete right bundle branch block was found in $11 \mathrm{pa}-$ tients $(2.8 \%)$. Transient complete atrioventricular block (AVB) was observed in 3 patients at postoperative days 3 (2 patients) and 4 (1 patient) before discharge. All of these patients regained sinus rhythm after a 3- to 5-day short course of corticosteroid therapy. None of these patients required temporary or permanent pacemaker implantation. One pericardial effusion occurred 4 days after operation and required repeated pericardial drainage.

The total operative time was less than 90 minutes, and the time for device implantation ranged from 5 to 60 minutes (17.8 \pm 8.7 minutes). All patients were extubated within 2 hours after the operation. In recent operations, we have begun to extubate patients on the table. Almost all patients were discharged 3 to 5 days after operation.

\section{Conversion to Conventional Open Repair With Cardiopulmonary Bypass in 15 Patients}

Aortic insufficiency from aortic prolapse occurred in $5 \mathrm{pa}-$ tients. Moderate aortic insufficiency occurred in 3 patients after the left disk was released, and aortic insufficiency occurred immediately after the delivery sheath was inserted in the LV cavity in 2 patients. The undetected aortic cusp 

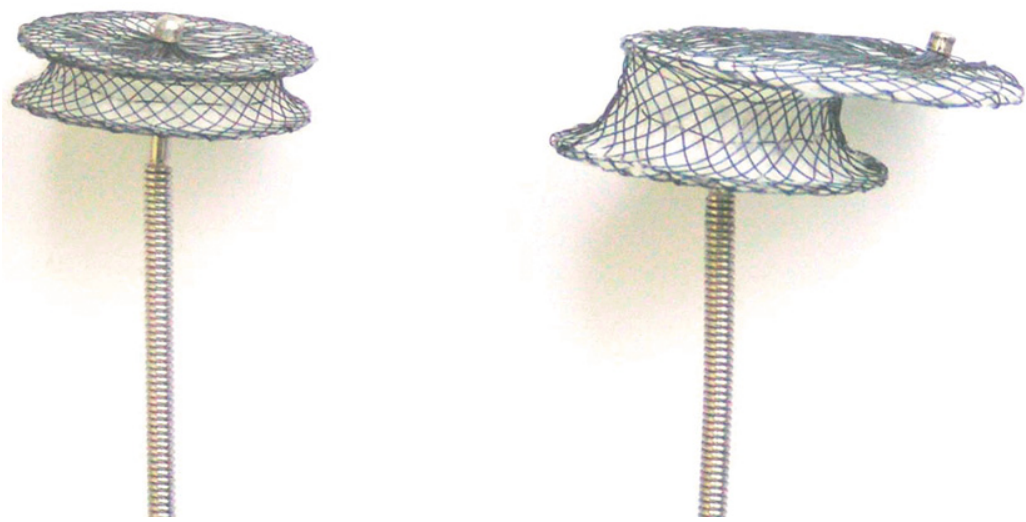

FIGURE 1. Concentric occluder (left) and eccentric occluder (right).

prolapse was confirmed in all 5 patients during open repair. Aortic insufficiency remained mild after open surgery.

Three patients had residual shunts. The interventricular shunt remained after the complete release of disks. During open surgery, membranous aneurysms and multiple openings in the right side were found in all 3 patients. There was a discrepancy of preoperative TEE findings and intraoperative findings leading to inadequate assessment.

Two patients had RV outflow tract obstruction. A new pressure gradient of 20 to $40 \mathrm{~mm} \mathrm{Hg}$ in the RV outflow tract

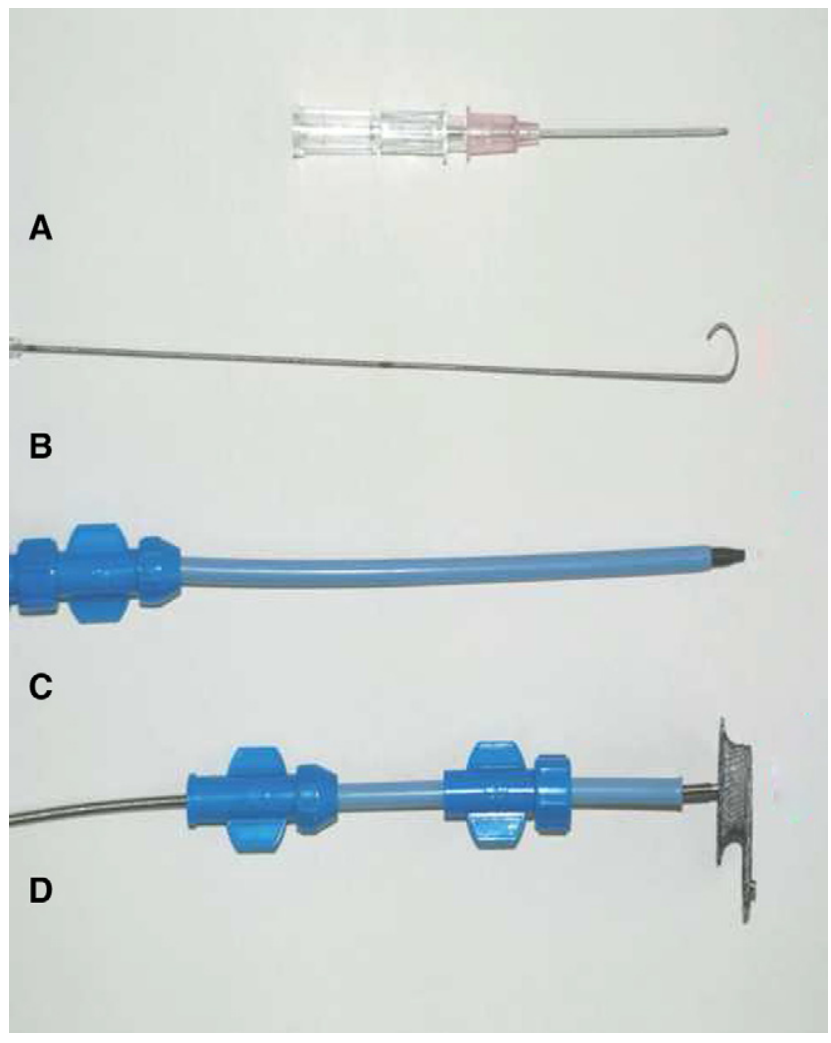

FIGURE 2. Delivery system: A, $18 \mathrm{G}$ trocar. B, Guidewire. C, Dilator and delivery sheath. D, Loading sheath with an eccentric occluder. was detected by TEE after device deployment. Systolic thrills could be felt on the surface of the RV free wall along the RV outflow tract. Abnormal hypertrophic muscle bundles were found pushing into the ventricular cavity by the disk, resulting in stenosis of the outflow tract.

The guidewire failed to cross the VSD in 2 patients. Despite repeated guidewire attempts and different puncture sites, the guidewire failed to pass through the VSD. Direct visual examination of VSDs revealed the puncture points; the VSD opening on the LV side and the VSD aneurysmal opening on the RV side were not in the same axis.

Abnormal occluder plasticity was found in 2 patients. In 1 patient, although there was no residual interventricular shunt, a wide range of occluder motion was observed. We chose open repair out of concern that the device might become loose in the future. We found the wide range of motion was caused by the weak and friable wall of the membranous aneurysm. Device distortion was found in 1 patient because the device was too big and crowded in the tunnel-like membranous aneurysm.

Severe arrhythmia occurred in 1 patient immediately after the guidewire passed through and touched the PMVSD tissues. The arrhythmia stopped spontaneously after removal of the guidewire. However, arrhythmia recurred during

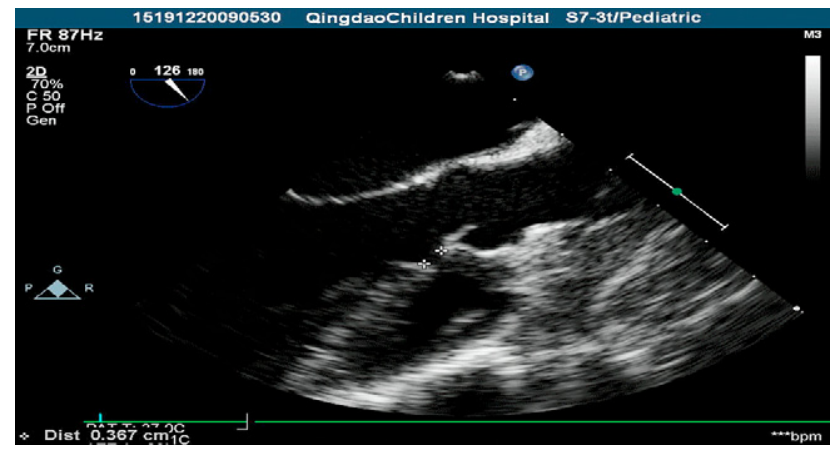

FIGURE 3. Long-axis view of VSD from TEE (almost no rim between VSD and aortic valve). 


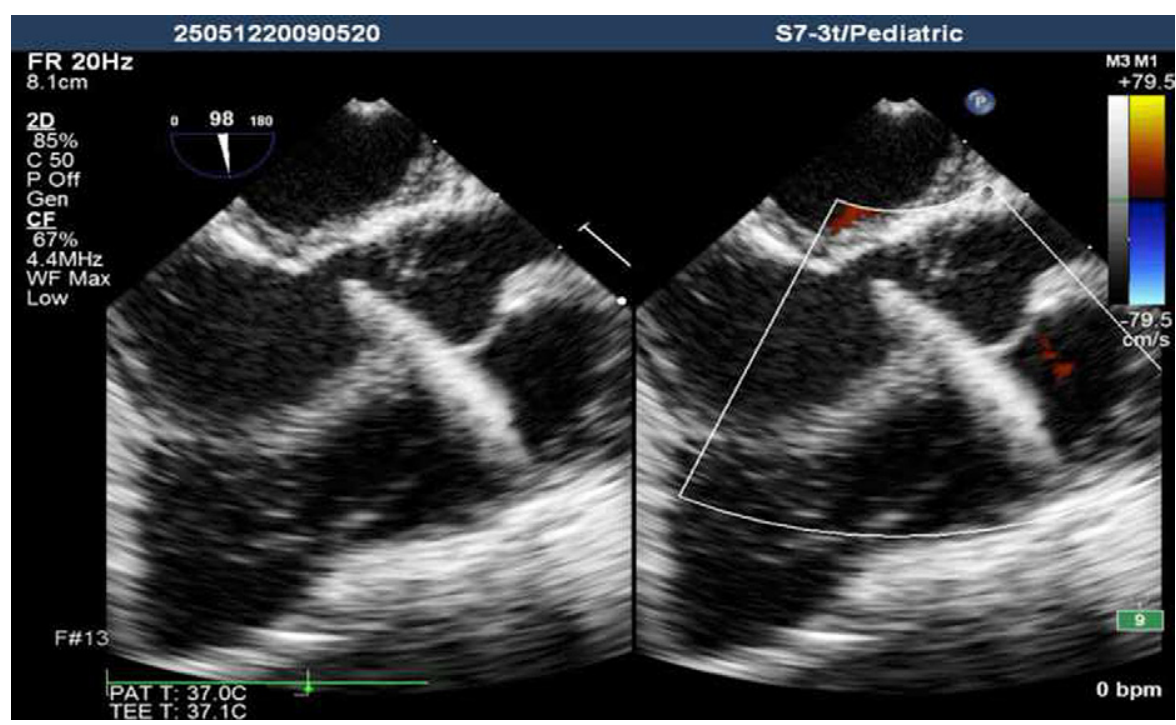

FIGURE 4. Guidewire through VSD.

subsequent attempts, an open surgery was performed. Sinus rhythm was regained after releasing the aortic clamp. It remains unknown why the heart reacted in this manner.

\section{Follow-ups}

There is a standard protocol for following up these patients. Patients were asked to return once per month in the first 3 months and then once every 3 months. Echocardiography to detect the position of the occluder, tricuspid and aortic valvular motions, and residual shunt; electrocardiography to detect arrhythmias; and chest radiography to compare the cardiothoracic ratio were performed at each follow-up. Each center had at least 2 doctors who were specially appointed to perform this work.

The follow-up rate was $100 \%$. The follow-up period ranged from 3 months to 2 years (14.6 \pm 6.2 months).
Patients took aspirin for 3 months at a dosage of 3 to $5 \mathrm{mg} / \mathrm{kg} / \mathrm{d}$. Follow-up was established for each patient.

Seven patients $(1.8 \%)$ presented with petechiae or purpura and improved after aspirin withdrawal for 3 to 5 days, possibly from aspirin allergy. Nine of the 13 patients with newly developed trivial or mild tricuspid regurgitation showed decreased regurgitation. Incomplete right bundle branch block resolved in 6 of 11 patients, and the other 5 patients remained stable. There was no new tricuspid regurgitation or arrhythmia detected in the follow-up.

Up to the last follow-up, no residual shunt, new or aggravating aortic regurgitation or tricuspid regurgitation, obstruction of left or RV outflow tract, or device dislocation was detected. There was also no thrombosis or hemolysis. The lower sternal incisions also caused minimal cosmetic concern.

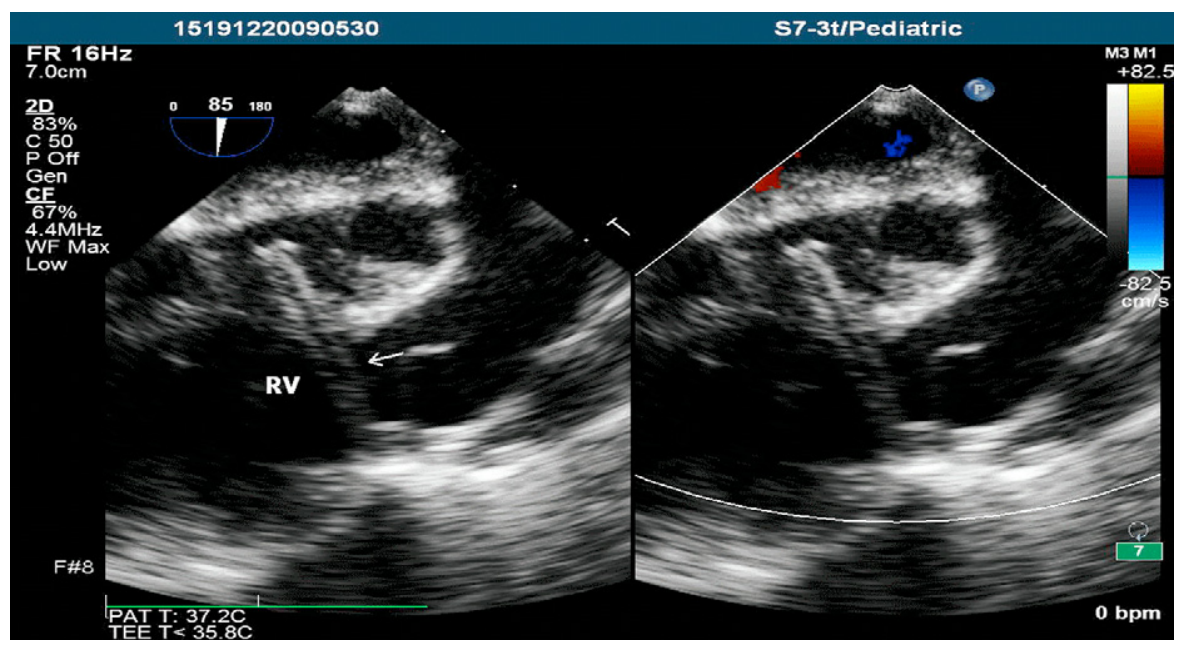

FIGURE 5. Delivery sheath through VSD. $R V$, Right ventricle. 


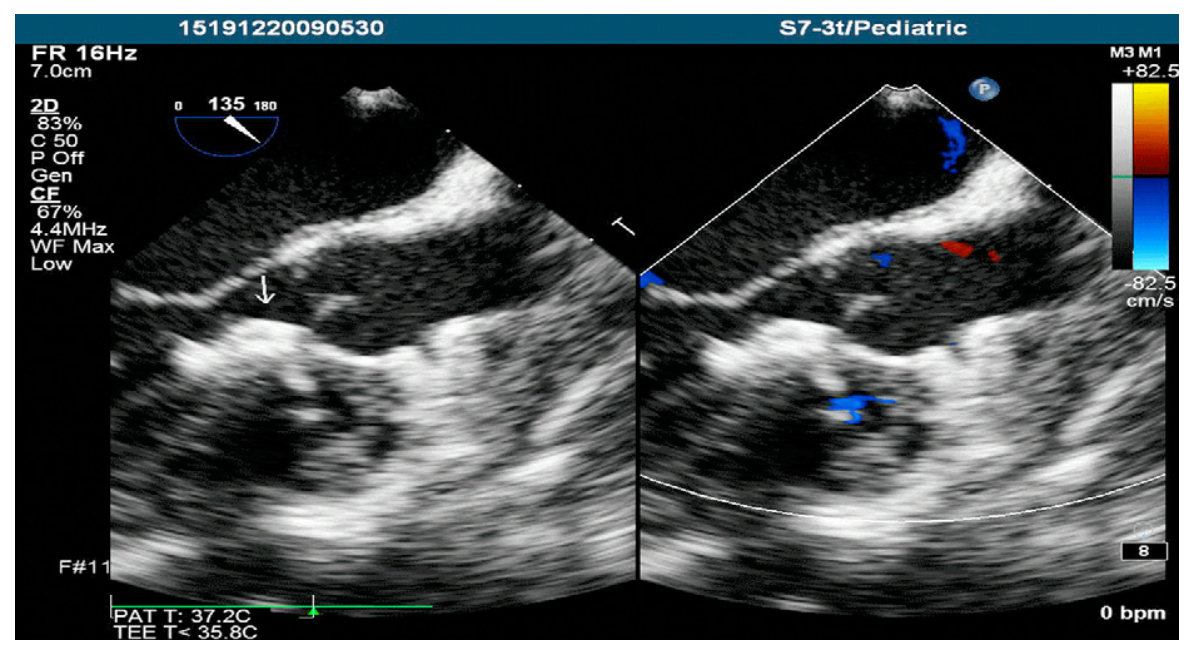

FIGURE 6. The left eccentric disk is released, and the right eccentric disk is still in the sheath.

\section{DISCUSSION}

Compared with conventional open closure and transcatheter closure of VSD, the advantages of PVDC of VSD seem to be obvious. First, this technique eliminates the potential complications of CPB, with less bleeding, surgical trauma, and psychologic and cosmetic concern from scar formation. Second, there is no radiation or femoral arterial injury from guidewire and sheath insertion when compared with transcatheter intervention. Third, the procedure is not constrained by a patient's weight and age as in the case of transcatheter closure. With 3-dimensional stereo imaging, this technique should be even easier and simpler.

In 1998, Amin and colleagues ${ }^{14}$ first introduced the principle and feasibility of PVDC of VSD in canine models with special occluder without CPB under the guidance of epicardial echocardiography. Later, Bacha and colleagues ${ }^{4}$ published their experience of PVDC of muscular VSD under TEE guidance with median sternotomy or subxiphoid mini- mally invasive incision. However, clinically, PVDC of VSD has been limited in patients with muscular VSD during the past 10 years. In 2007, Xing and colleagues ${ }^{6}$ reported their first application of PVDC in PMVSDs with a specially modified delivery system via a 3- to 4-cm subxiphoid incision. There was no complication reported in their series. Shortly thereafter, many similar cohorts were reported by other Chinese doctors. ${ }^{7-13}$

The key point in successfully using this technique is to establish the correct delivery pathway through the VSD into the LV cavity. The details of this technique were previously reported by our group. ${ }^{12}$ In case of closure failure or inappropriate selection of cases for device closure, conventional full sternotomy should be used to close the VSD under CPB. Conversion to open surgical repair in this cohort was mainly because of improper patient selection, and these cases occurred in the early phase of our learning period. There was no device failure or other severe complications related

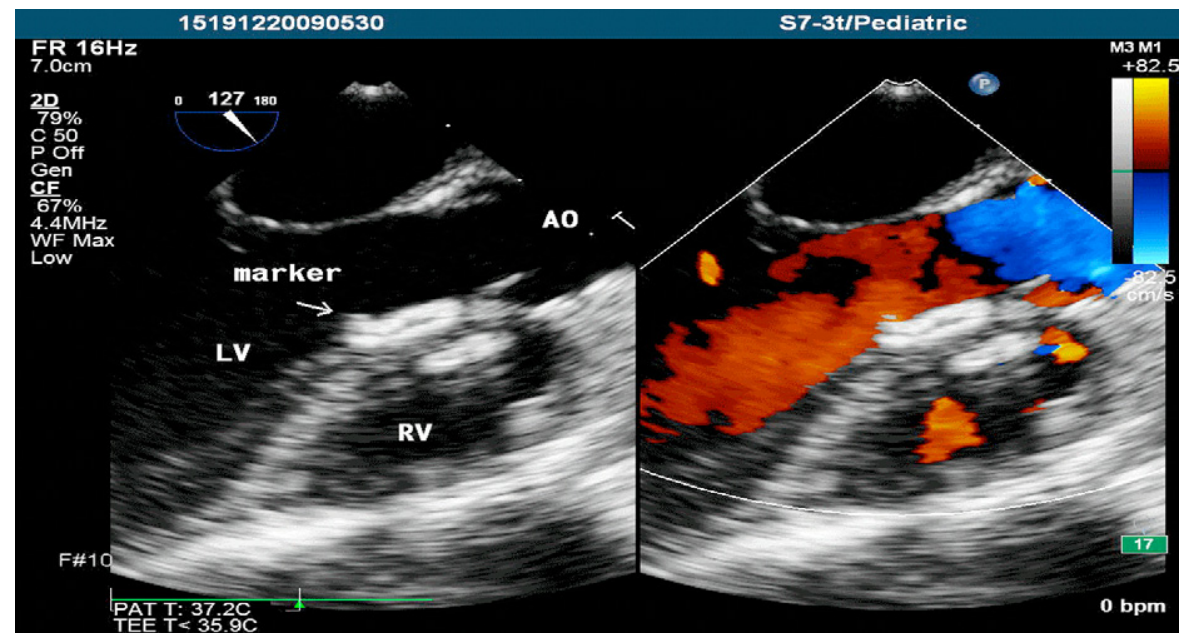

FIGURE 7. Completely released device and successful VSD closure with an eccentric occluder. $R V$, Right ventricle; $L V$, left ventricle; $A O$, aorta. 
to device closure, such as increased aortic regurgitation, significant $\mathrm{AVB}$, and refractory bleeding. Nevertheless, the real-time TEE monitoring by an experienced cardiologist and the dexterity of surgeons in handling the device should be emphasized. According to our experience, the operators should be familiar with the technique after 20 to 30 operations.

Aortic insufficiency is a severe complication of VSD device closure and most commonly occurred. The eccentric side of the occluder can be easily manipulated to face the heart apex and thus avoid the risk of aortic regurgitation in those VSDs that are closer to the aortic valve. The shorter delivery pathway and the ease of handling the controllable set enable the operators to advance the delivery system to the target defect and accurately deliver the device. In comparison, this is relatively more difficult to achieve in transcatheter intervention because of the long delivery pathway and obscure position from an indefinite radiologic angle difference related to the variation of the VSD position. It may be an innovation in eccentric occluder deployment that avoids this complication. In our experience, many VSDs $(45.8 \%)$ were close to the aortic valves, but the eccentric occluders were successfully deployed.

Far from our initial concern, no complete AVB or left bundle branch block occurred in our group compared with the transcatheter intervention. ${ }^{15-21}$ As mentioned earlier, PVDC of PMVSD requires only a short pathway and an easily controllable set. The guidewire and sheath need to be advanced less than $5 \mathrm{~cm}$ (from the RV free wall to the $\mathrm{LV}$ cavity), vertically crossing the VSD. Therefore, the device can be deployed in a single try in most circumstances, without repeating the maneuver. This may be the important reason why no immediate serious AVBs occurred in our patients.

Perhaps there were no late AVBs in our patients because our modified delivery system may reduce ribbing and compressing the tissues near the conductive bundles around the VSD. Furthermore, the occluders that were used were often no more than $1 \mathrm{~mm}$, rarely $2 \mathrm{~mm}$ larger than the VSD diameter, and almost no oversized occluders have been used. However, there are no direct data about the mechanisms involved in the occurrence of complete AVB after device closure of a PMVSD. The current rate of complete AVB after VSD closure by interventional cardiologists is $1 \%$ to $5 \% .{ }^{15-20}$ Predescu and colleagues ${ }^{21}$ reported an occurrence rate of $22 \%$, much higher than all other published studies. However, there were differences in the selection of their patients from published reports. ${ }^{15-20}$ Half of their patients were in our category of contraindications, such as nonrestrictive VSDs, infants with large VSDs, and severe pulmonary hypertension. Furthermore, the device deployment maneuver we used was completely different from theirs. In addition, only 20 patients were included in their group in approximately 3 years. We do not know whether the small number of patients might limit cumulative experience.
We have also operated successfully in some patients with VSD who were turned down by cardiologists for transcatheter closure. This may imply the new technique can be used in a wider patient selection.

Up to the present, we are not able to delineate the definitive indications and contraindications of this technique. Not all PMVSDs are suitable for PVDC. ${ }^{15-20}$ According to our experience, patients with the following conditions are not suitable for this technique: nonrestrictive VSD, VSD associated with aortic prolapse, large VSD in neonates or young children associated with severe pulmonary hypertension, VSD with tricuspid anomaly, and poor echogenic response. Recently, we have emphasized studying the outcome of so-called marginal cases. With accumulation of experience and communication with others, especially with pioneers such as Drs Amin and Bacha, we may be able to redefine the indication and contraindications. With more follow-up data and experience, definitive indications and contraindications will be achieved.

\section{Clinical Limitations}

Although the techniques of PVDC of PMVSD seem to be safe in the mid-term follow-up, it is not known whether they are safe in the long term, especially the late complication of complete AVB and the heart function. More experience and long-term follow-up are mandatory to assess the actual safety and effectiveness of this procedure as an alternative to conventional surgery and transcatheter intervention. On the other hand, the restrictive PMVSDs were those with a diameter between 3 and $12 \mathrm{~mm}(5.1 \pm 2.6 \mathrm{~mm})$. Although more than 400 patients have been successfully treated without serious complications, we do not have more data to elucidate the exact underlying morphologic criteria for size and location of the VSD suitable for this procedure. This is a new technique for VSD treatment that is gradually improving. Furthermore, this is an experience-based and not a laboratory-based summary. Three-dimensional echocardiography and accumulation of experience should perfect this technique.

\section{ADDENDUM}

The patients in our group have been followed for 6 to 30 months (21.3 \pm 5.7 months) with no major complications. There are now 27 centers in China undertaking this procedure, with approximately 2000 patients accepting this new treatment.

\section{References}

1. Amin Z, Gu X, Berry JM, Titus JL, Gidding SS, Rocchini AP. Perventricular closure of ventricular septal defects without cardiopulmonary bypass. Ann Thorac Surg. 1999;68:149-53.

2. Amin Z, Danford DA, Lof J, Duncan KF, Froemming S. Intraoperative device closure of perimembranous ventricular septal defects without cardiopulmonary bypass: preliminary results with the perventricular technique. $J$ Thorac Cardiovasc Surg. 2004;127:234-41.

3. Amin Z, Gu XP, Berry JM, Bass JL, Titus JL, Urness M, et al. New device for closure of muscular ventricular septal defects in a canine model. Circulation. 1999;100:320-8. 
4. Bacha EA, Cao QL, Starr JP, Waight D, Ebeid MR, Hijazi ZM. Perventricular device closure of muscular ventricular septal defects on the beating heart: technique and results. J Thorac Cardiovasc Surg. 2003;126:1718-23.

5. Bacha EA, Cao QL, Galantowicz ME, Cheatham JP, Fleishman CE, Weinstein SW, et al. Multicenter experience with perventricular device closure of muscular ventricular septal defects. Pediatr Cardiol. 2005;26:169-75.

6. Xing QS, Zhuang ZY, Pan SL, Duan SH, Rong YB, Li SD. Minimally invasive transthoracic device closure of perimembranous ventricular septal defect with a newly designed delivery system in 11 children. Chin J Exp Surg. 2007;24: 1135-6.

7. Gan CP, An Q, Lin K, Tang H, Lui RC, Tao KY, et al. Perventricular device closure of ventricular septal defects: six months results in 30 young children. Ann Thorac Surg. 2008;86:142-6.

8. Li F, Chen M, Qiu ZK, Lu J, Wu Wh. A New minimally invasive technique to occlude ventricular septal defect using an occluder device. Ann Thorac Surg. 2008;85:1067-71.

9. Zeng XJ, Sun SQ, Chen XF, Ma XJ, Luo YH, Lim YP, et al. Device closure of perimembranous ventricular septal defects with a minimally invasive technique in 12 patients. Ann Thorac Surg. 2008;85:192-4

10. Xing QS, Zhuang ZY, Pan SL, Rong YB, Duan SH, Hou KF, et al. Perventricular device closure of ventricular septal defect with a newly designed delivery system on beating hearts. Chin J Thorac Cardiovasc Surg. 2008;24:279.

11. Lin K, Gan CP, Tang H, Song HB, Shi YK, Zhuang ZY, et al. Perventricular device closure 39 cases of non-muscular ventricular septal defects. Chin J Thorac Cardiovasc Surg. 2008;24:367-9.

12. Xing QS, Pan SL, Zhuang ZY, Rong YB, Li SD, Cao Q, et al. Minimally invasive perventricular device closure of an isolated perimembranous ventricular septal defect with a newly designed delivery system: preliminary experience. $J$ Thorac Cardiovasc Surg. 2009;137:556-9.
13. Gan CP, Lin K, An Q, Tang H, Song HB, Lui RC, et al. Perventricular device closure of muscular ventricular septal defects on beating hearts: initial experience in eight children. J Thorac Cardiovasc Surg. 2009;137:929-33.

14. Amin Z, Berry JM, Foker JE, Rocchini AP, Bass JL. Intraoperative closure of muscular ventricular septal defects in a canine model and application of the technique in a baby. $J$ Thorac Cardiovasc Surg. 1998;115:1374-6.

15. Butera G, Carminati M, Chessa M, Piazza L, Abella R, Negura DG, et al. Percutaneous closure of ventricular septal defects in children aged $<12$ : early and midterm results. Eur Heart J. 2006;27:2889-95.

16. Thanopoulos BD, Tsaousis GS, Karanasios E, Eleftherakis NG, Paphitis C. Transcatheter closure of perimembranous ventricular septal defects with the Amplatzer asymmetric ventricular septal defect occluder: preliminary experience in children. Heart. 2003;89:918-22.

17. Masura J, Gao W, Gavora P, Sun K, Zhou AQ, Jian S, et al. Percutaneous closure of perimembranous ventricular septal defects with the eccentric Amplatzer device: multicenter follow-up study. Pediatr Cardiol. 2005;26:216-9.

18. Carminatil M, Butera G, Chessa M, De Giovanni J, Fisher G, Gewillig M, et al. Transcatheter closure of congenital ventricular septal defects: results of the European Registry. Eur Heart J. 2007;28:2361-8.

19. Butera G, Carminati M, Chessa M, Piazza L, Micheletti A, Negura DG, et al. Transcatheter closure of perimembranous ventricular septal defects early and long-term results. J Am Coll Cardiol. 2007;50:1189-95.

20. Holzer R, de Giovanni J, Walsh KP, Tometzki A, Goh T, Hakim F, et al. Transcatheter closure of perimembranous ventricular septal defects using the Amplatze membranous ventricular septal defect device occluder: immediate and midterm results of an international registry. Catheter Cardiovasc Interv. 2006;68:620-8.

21. Predescu D, Chaturvedi RR, Friedberg MK, Benson LN, Ozawa A, Lee KJ. Complete heart block associated with device closure of perimembranous ventricular septal defects. J Thorac Cardiovasc Surg. 2008;136:1223-8. 